\title{
From Miseducation to Education in the Global Canadian Indigenous Context
}

\author{
Carol A. Mullen \\ Virginia Tech, USA
}

\begin{abstract}
Education in today's global Canadian Indigenous context is the subject of this review essay. Issues of educational injustice and systemic racism-taken up in the Indigenous literature - are presented. The analysis of critical sources led to binaries, such as miseducation-education, and associated theme From Miseducation to Education animated by the overarching construct De/colonization (of schools and society). Salient concerns in colonial Canadian schooling and broader societal systems were identified in addition to pedagogies for deconstructing colonial settler mindsets, decolonizing socializing influences, and transforming people, institutions, and society. It was also found that the movement from miseducation to education necessitates confronting systemic disorders that are embedded within the human psyche and spaces of formal learning, as reflected in colonial classrooms, policies, programs, and interactions. Transformative possibilities, which are expressed in teaching and learning, education and social policy, and educator and public understanding, are briefly addressed.
\end{abstract}

\section{Introduction}

The purpose of this review study was to discover perspectives in the Indigenous literature on educational issues within Canadian society today. The research question shaping this study was, What issues of an educational nature within contemporary Canada are described in the Indigenous literature? In response, continuing educational and social injustices and efforts designed to bring about transformation, reflected in the critical sources and by voices of resilience, are briefly presented. A focal point advanced for this complex set of dynamics is what I refer to as the miseducation-education binary, an ingrained tension in society and racial politics.

This article is part of a larger study of Indigenous education in settler societies. Resulting publications that inform this writing include my book entitled Canadian Indigenous Literature and Art: Decolonizing Education, Culture, and Society [1]. However, the current writing is updated, and it offers a succinct snapshot of systemic racism's impact on vulnerable groups, most recently made glaring by the COVID-19 outbreak, due to age-old socio-economic inequalities for Canada's First Nations, Inuit, and Métis communities. During the pandemic, increases in domestic violence were reported against
"Indigenous women and gender-diverse people," with access to education, justice, food, and vocations all areas of stated impact [2] (p. 11). "Calls for justice," cited in the report, refer to a national inquiry that was supposed to motivate Canadian authorities to take seriously the "surge in violence" against "missing and murdered" Indigenous females and the impact on lives [2] (p. 2).

For the current study, pertinent sources $(\mathrm{N}=165)$ located between 2017 and 2021 via library databases and Google Scholar were analyzed. These included empirical and conceptual studies and documents (e.g., policy reports). Descriptors (e.g., Canada, education, Indigenous) were derived from the research question and search results.

Across the literature reviewed, threats to Indigenous rights and wellbeing are exposed, including miseducation, tribal injustice, dispossession, conflict, and discrimination. Another finding was that the Indigenous-White binaryrooted in colonialism and dynamics of subjugation, power, and control-reveals continuing tensions between Indigenous peoples and colonial settlers in education and schooling, among other domains.

Stigmatization of tribal sovereignty extends to education, Indigenous rights, citizenship, ownership, and responsibility. Critical scholars and associations, Indigenous and non-Indigenous alike, support tribal rights and causes, such as inclusive education systems and rightful land ownership. To deconstruct mindsets resulting from colonial ways of thinking and behaving, critiques "unsettle" colonialization and its harmful effects on Indigenous communities. A lack of accountability perpetuated by settler societies is called out in the name of tribal justice [3], [4], [5].

Colonial nations and settlers preserve a racial politics of color. In Canada, dominating/subjugating relations ensure the continuation of a white/ Indigenous binary paradigm of race. Through opposition implied in similar imposing binaries (e.g., western/Indigenous and settler/Indigenous), colonial social order supports paradigms of dominance [5]. Binaries are fundamental to thought and language systems, which strictly define these races in relation to the other. Secondary binaries like superior/inferior reinforce a colonial hierarchy and racial stereotypes. The binary field of white/Indigenous racial polarization reproduces the cultural typecasting of Indigenous subservience and culturally approved opposites, thereby eliminating possibilities of anti- 
racism, healing, and reconciliation. Settler colonialism maintains the image of First Peoples as inferior and aberrant, making white people superior and whiteness the norm and hence normal [5].

Six thematic binaries resulted from the interpretive analysis of select sources:

- miseducation-education

- Colonization-decolonization

- Indigenous injustice-Indigenous justice

- Dispossession-possession

- Discrimination-protection and

- Conflict-accord

The first binary and theme (from miseducation to education) is this article's focal point of discussion.

Curriculum and programming emphases in some of the studies reviewed take up pedagogical challenges of (a) deconstructing colonial settler mindsets and (b) decolonializing learning in classrooms. Elsewhere I have identified practical applications in classrooms and communities (e.g., [1]). Notably, the colonization-decolonization binary is overarching in importance-it underlies and influences the other binaries. Thus, each binary is embedded in colonialism and the movement from colonization to decolonization.

Like the From Miseducation to Education theme brought forward here, my findings from the Indigenous literature are more complex than the against/for binaries imply. Each binary hinges on a problem (e.g., miseducation rooted in colonization) in opposition to a destabilizing counterforce (e.g., education advanced by decolonization). A picture transpires of core issues across binaries that reveal systemic disorders and transformative possibilities.

\section{Miseducation-Education Binary}

Commonly, Indigenous students' needs are not met in schools and institutions of higher education. As one issue, standardization and accountability in Canada have overtaken culturally responsive, equitable education [6]. International testing and rankings justify global competitiveness for Canada and other nations through which Indigenous groups are subjugated [1], [3]. Racial differences in educational outcomes are stark, worldwide. A significant inequality between Indigenous and nonIndigenous youth is in achievement, success, and life prospects [7], [8].

Across Canada, only about $40 \%$ of Indigenous youth attending high schools on reserves have graduated. These outcomes starkly contrast with the $70 \%$ for those attending off-reserve schools, which was higher for Métis graduates $(80 \%)$. For nonnative students, Canada's high school graduation rate was $90 \%$ [9]. Unfortunately, it is expected that Indigenous students who do not graduate from onreserve and off-reserve schools will encounter "a future plagued by unemployment, poverty, limited social and economic opportunities, crime, health problems and an ongoing reliance on federal and provincial government support for housing" (p. 3) [9].

This "reform agenda" points to the need for multipronged solutions. Recommendations include accounting for reserve school funding, tribe/band responsibility, Indigenous and Northern Affairs' capacity at the regional level, and incremental reforms [9]. Collaboration is called for among governments, chiefs, and bands to bring about improved achievement for Indigenous students in core subjects (reading, math, and science). These subjects are "not culturally specific," although study of "Aboriginal languages and cultural studies" is otherwise expected [9]. From my review, takeaways are that (a) widespread inappropriate schooling of Indigenous persons has severe penalties, and (b) implications are stark in education and life for Indigenous futurity and Canada's record of inclusion.

\subsection{Trends and factors}

Trends indicating educational disparity within and beyond Canada's borders include the following:

- An ongoing ethnic gap in educational levels (Indigenous school enrollments, school performance, and literacy levels are all low while attrition is high).

- Underwhelming (substandard) academic achievements compared with other ethnic group.

- A discrepancy in educational attainment due to ethnicity, parental education, low-socioeconomic status, and geography.

- An increase in Indigenous persons without a high school diploma. [1], [7], [9], [10], [11].

Canadian provincial ministries of education have been responding to the educational inequalities in Indigenous achievement and treatment. In Ontario, Indigenous education policies integrate Indigenous content in curriculum [10], although the reliability and authenticity of the content has been questioned [12]. But policy-driven standards have not evidenced educational gains for Canadian Indigenous students [6]. A calamity of colonialism is the failure to serve 
Indigenous groups equitably and successfully in 21 st century democracies. Low academic attainment continues for Native American students. High-stakes testing in North America has neither improved Indigenous students' academic achievement nor bolstered cultural knowledge, identity, capital, and opportunities [3], [8], [13].

Systems of education, justice, child welfare, and health "[have] failed Aboriginal peoples profoundly" (p. 813), [4]. Indigenous youth struggle to complete education (secondary and postsecondary) due to low self-confidence, poor academic preparation, scarce financial resources, absence of educated role models, and campus racism. However, barriers to racial equity are also subtle and systemic. When considered from the official provincial perspective, the result was that "robust education policy related to racial equity" is lacking in Canadian education, based on analyses of Ontario and British Columbia's documents using critical race theory (p. 159), [14].

Tribal injustices in education today are rooted in colonial legacy. Residential school policy legitimated the extraction of 86,000 Indigenous children from their families and placement in nationwide residential schools. In 1883, Hector Langevin, Public Works Minister of Canada, declared that children had to be removed from their families to be educated "properly" and "civilize[d]" [15]. So "they came for the children" [15]. From 1879 and 1996, the Canadian Indian residential school system operated [4]. The Canadian government's Indian Affairs and Northern Development funded this systemic racist initiative, which Christian churches ran. The motiveuncovered by the Truth and Reconciliation Commission of Canada (TRC)—was displacement and appropriation of Indigenous lands and resources, thereby disposing of the "Indian problem"; this motivation played out in the colonial Canadian governments" "Aboriginal policies" [16].

The Indian Residential Schools Settlement Agreement, enacted in 2006, established the TRC [17]. (The settlement, a class action suit, resulted in Canada's financial compensation of former residential students for damages incurred.) A mandate of the commission was to educate the public about the nation's history of residential schooling. It was found that the continuation of its bleak legacy in modern times "is reflected in the significant disparities in education, income, and health between Aboriginal people and other Canadians - disparities that condemn many Aboriginal people to . . . troubled lives," in addition to "the intense racism and the systemic discrimination Aboriginal people regularly experience" and bigoted policy [17].

To move Canadian society from history to legacy to reconciliation, "constructive action" must be deployed in education and broader systems - culture, language, health, child welfare, justice, and economics [17]. Disrupting colonialism and resolving its negative impact on Indigenous education cannot happen in isolation, for the problem affects all Indigenous life systems ([4], [17]. According to TRC Chair Justice Murray Sinclair, the non-native public must be educated differently about Indigenous peoples, and not just their distinctive culture and ways of knowing and being. To become accountable to settler impact, Canadian educational institutions would need to take responsibility for colonialism and racism being firmly embedded at all levels of society [17]. Guidance for undergoing and achieving reconciliation is conveyed as principles, in the spirit of bringing about healing as a benefit of social transformation [15], [17].

To progress with reconciliation in education, conventional structures of power would be decolonized, including research practices and methodologies [4], [14]. Colonial institutions would relinquish power, privilege, and/or land and resources, essentially capital that signify stolen property and lives. Settlers-white, brown, and Black-would understand that "critical consciousness (of colonization)" cannot be the sole aim that, from a critical perspective, is about relieving "settler[s] of feelings of guilt or responsibility" regarding their "complicity in settler colonialism" (p. 10), [5].

\subsection{Policy and curriculum}

Canadian policy and curriculum play a vital role in overcoming assimilationist policies and practices that maintain historical calamities like the residential schools and governmental decision making [4]. Decolonizing policy and curriculum is essential for preventing ongoing fallout and building relational trust between Indigenous and non-Indigenous peoples; importantly, "policy-driven intervention in schools" (p. 545), [18] would allow for a shared future to be imagined [4]. Provincial ministries of education have been responding to the pressure to enact profound educational change. In Ontario, commitments translate into education policies and directives to integrate content reflective of "Indigenous histories, cultures, and perspectives" throughout curriculum (p. 2), [10].

However, Canada's trajectory toward decolonizing curriculum is entangled in (neo)colonization. Analysis of Ontario's official, policy-supported grades 1-12 science curriculum illustrates such dynamics [12]. While "Aboriginalrelated content" and knowledges are incorporated, Euro-Western "colonial ideas" of modern science dominate. Because the curriculum "does not accommodate Aboriginal students' learning and creates a stereotype of Aboriginal knowledge as antiquated," it evidences "neo-colonialism" (p. 20, [12]. A study of science within a colonizing 
framework [19] indicated that "Science was used to support an ideological and racist justification for subjecting Indigenous cultures and ways of knowing" and that "The racism inherent in this evolutionary paradigm contributed to the genocidal policy towards Aboriginal peoples" (p. 77), [12].

More optimistically assessing Ontario's Indigenous education policy, Milne (2017) affirmed the embedding of "Indigenous content into the provincial curriculum." But Milne did express not knowing if the "Indigenous policy directives" are in fact "impacting student learning" (p. 13). Neocolonialism (like colonialism) breeds damaging stereotypes, undercutting Indigenous knowledges and epistemologies, culture and spirituality with images of brutality [12], [19].

\subsection{Agency and educator}

Supporting Indigenous rights, the UN (2018) articulated educational and agency frameworks for systems of education and healthcare. Assertions include the right of Indigenous peoples, free of discrimination, to "establish and control their educational systems and institutions" and "[educate] in their own languages [using] their cultural methods of teaching and learning" (p. 7). Another such right centers on Indigenous children's "special vulnerability and the importance of education for their empowerment" (p. 8). The expectation is that states (provinces) will protect against children being economically exploited or having their education undermined or development harmed in any way.

Researchers of Indigenous issues offer different perspectives on, and approaches to, decolonizing education. Some postsecondary faculty assert agency by cultivating students as critically aware, raceconscious, human rights activists capable of expressing agency themselves. Among these pedagogues, an attempt is made to repair damaged relations with tribes. Interventionist pedagogies for decolonizing education, complete with applications, are detailed in select sources [1], [18], [20].

\subsection{Powerlessness and atrocity}

All such initiatives are pitted against false ideas and moral atrocities that plague colonial systems. In 1991, the Royal Commission on Aboriginal Peoples' (RCAP) independent public inquiry in Canada investigated issues of Canadian Indigenous status, addressing education, health, and housing. Negative systemic biases were identified that reduce Indigenous peoples and their learning to a colonial settler education. Naming Canada's residential schooling as but one tragic example, in 1996 the RCAP warned of "powerful but grievously false premises [taking] over public institutions and render[ing] them powerless" and of "democratic populations to tolerate moral enormities" (p. 579, as cited in [1]). Society's huge capacity for miseducation will likely always require the moral responsibility to monitor disturbing realities was a clear implication.

\section{Insights revealed}

Indigenous sources revealed that tribal injustices - an enduring problem of humanity - is a societal and educational responsibility. Miseducation, tribal injustice, dispossession, conflict, and discrimination were identified as critical components of colonization, as well as threats to Indigenous wellbeing and longevity. Degrees of recognition were evidenced around these ideas; thus, treatment is variable of Indigenous agency to advance conflict resolution, defeat systemic racism against tribes, and restore Indigenous rights. Decolonization efforts center justice for tribes on the restoration of land and tribal sovereignty. Resistance, consciousness-raising, partnership, trust, and bridging the divide can promote reconciliation in transnational contexts. Building awareness by decolonizing education despite constraints is a pedagogical tenet, with advocacy for transforming settler minds on behalf of reconciliation.

The scholars and associations cited, among many others, admonish the deficit-based, culturally biased views binaries germinate, such as of Indigenous students and their heritage (Castagno \& Brayboy, 2008). There is encouragement for troubling the Indigenous-white binary and educating about offensive stereotypes (Mullen, 2020). Unsettling colonial discourses can enable relations between settlers and Indigenous peoples to be reimagined beyond those restricted to their binary construction.

\section{Conclusion}

Based on this review, Indigenous literature conveys that educational and social justice is complex and elusive and, paradoxically, that data clearly indicate racial inequity trends. Furthermore, justice is a collective and global responsibility that needs to motivate authorities to act on behalf of Indigenous communities, guide governmental mandates and official education policy, and permeate institutions of learning. Through agency, advocacy, and solidarity in education and public life, tribal justice can become an impactful paradigm of change.

Indigenous and ally voices speak about colonialism as a crisis of humanity for which authorities, policymakers, educators, and all stakeholders must intervene. Indigenous futurity depends on the movement from miseducation to education as but one aspect of a global transnational reform project broadly known as decolonization. Educational institutions have a serious role to play in decolonizing the status quo [1] [13] [18] [20]. For the 
sake of future generations and the health of entire communities, it is time to educate for a just and inclusive world; invest in Indigenous education and youth engagement; and promote wellbeing through reconciliation, transformation, and healing.

\section{References}

[1] Mullen, C. A. (2020). Canadian Indigenous Literature and Art: Decolonizing Education, Culture, and Society, Brill, Netherlands.

[2] Native Women's Association of Canada. (2020). 'The Impact of COVID-19 on Indigenous Peoples', [Report, UN Special Rapporteur on the Rights of Indigenous Peoples, pp. 1-11]. https://www.ohchr.org/Documents/Issues/ IPeo ples/SR/COVID-19/IndigenousCSOs/Canada_Native_Wo men_Association_of_Canada.pdf (Access Date: June 26, 2021).

[3] Castagno, A. E., \& Brayboy, B. M. J. (2008). Culturally Responsive Schooling for Indigenous Youth: A Review of the Literature. Review of Educational Research 78, pp. 941-993.

[4] McGregor, D. (2018). 'From 'Decolonized' to Reconciliation Research in Canada: Drawing from Indigenous Research Paradigms', ACME: An International Journal for Critical Geographies 17(3), pp. 810-831.

[5] Tuck, E., \& Yang, K. W. (2012). Decolonization is not a metaphor. Decolonization: Indigeneity, Education \& Society 1(1), pp. 1-40.

[6] Kempf, A. (2016) The Pedagogy of Standardized Testing: The Radical Impacts of Educational Standardization in the US and Canada, Palgrave Macmillan, New York.

[7] Gordon, C. E., \& White, J. P. (2014). 'Indigenous Educational Attainment in Canada', International Indigenous Policy Journal 5(3), pp. 1-28.

[8] McCarty, T. L. (2018). 'So That Any Child may Succeed: Indigenous Pathways Toward Justice and the Promise of Brown', Educational Researcher 47(5), pp. 271-283.

[9] Anderson, B., \& Richards, J. (2016). 'Students in Jeopardy: An Agenda for Improving Results in Bandoperated Schools', [Commentary pp. 1-28]. dhowe.org/sites/default/files/attachments/research_papers/ mixed/commentary_444_0.pdf (Access Date: 3 March 2021)

[10] Milne, E. (2017). Implementing Indigenous Education Policy Directives in Ontario Public Schools: Experiences, Challenges and Successful Practices,' International Indigenous Policy Journal 8(3), pp. 1-22.

[11] United Nations (UN). (2017). 'State of the World's Indigenous Peoples: Education' (3rd vol., 1-216.). un.org/development/desa/indigenouspeoples/wp-content/u ploads/sites/19/2017/12/state-of-worlds-indigenous-people s_ iii_web2018.pdf (Access Date: 16 March 2021).

[12] Kim, E-J A. (2015) 'Neo-colonialism in Our Schools: Representations of Indigenous Perspectives in Ontario Science Curriculum', McGill Journal of Education 50(1), pp. 1-25.

[13] Faircloth, S. C., \& Tippeconnic, III, J. W. (2015). 'Leadership Development for Schools Serving American Indian Students', Journal of American Indian Education 54 , pp. $127-153$.

[14] George, R. C., Maier, R., \& Robson, K. (2020). 'Ignoring Race: A Comparative Analysis of Education Policy in British Columbia and Ontario,' Race Ethnicity and Education, 23(2), pp. 159-179.

[15] Truth and Reconciliation Commission of Canada (TRC). (2012). 'Canada, Aboriginal Peoples, and Residential Schools: They Came for the Children', [Report]. tolliday.weebly.com/uploads/2/4/9/3/24933340/ they_came_for_the_children.pdf (Access Date: 7 April 2021).

[16] Truth and Reconciliation Commission of Canada (TRC). (2015). 'Honouring the Truth, Reconciling for the Future: Summary of TRC Final Report', http://www.trc.ca/ assets/pdf/Honouring_the_Truth_Reconciling_for_the Future_July_23_2015.pdf (Access Date: 1 May 2021).

[17] Sinclair, M., Littlechild, W., \& Wilson, M. (2015). 'What We have Learned: Principles of Truth and Reconciliation', [TRC Report.] trc.ca/assets/pdf/resprinciples\% 20of\%20truth\%20and\%20reconciliation.pdf (Access Date: 6 March 2021)

[18] Aitken, A., \& Radford, L. (2021). 'Social Justice in the Classroom: If "Literature Is One Way to Make This Happen," Should Reading for Justice Be Required in Schools?', in C. A. Mullen, Handbook of Social Justice Interventions in Education. Springer, Cham, Switzerland, pp. 543-566.

[19] Kovach, M. (2009). Indigenous Methodologies: Characteristics, Conversations, and Contexts, University of Toronto Press, Toronto, Ontario.

[20] Kitchen, J., \& Taylor, L. (2021). 'Preparing Preservice Teachers for Social Justice Teaching: Designing and Implementing Effective Interventions in Teacher Education', in C. A. Mullen, Handbook of Social Justice Interventions in Education. Springer, Cham, Switzerland, pp. 955-980.

\section{Acknowledgements}

Mullen's (2020) book was awarded the 2021 Outstanding Book Award from the Society of Professors of Education; it resulted from the author's US Fulbright scholarship, which was sponsored in Toronto, Canada and funded by World Learning, a program of the US Department of State. 